\title{
NFAT5 inhibits invasion and promotes apoptosis in hepatocellular carcinoma associated with osmolality
}

\author{
X. QIN ${ }^{\ddagger}$, Y. WANG ${ }^{\ddagger}$ J. LI, Y. XIAO, Z. LIU* \\ Department of hepatobiliary surgery, Zhongnan hospital of Wuhan University, Wuhan 430071, Hubei, P.R. China \\ ${ }^{*}$ Correspondence: liuzs53@sina.com \\ ${ }^{*}$ Contributed equally to this work.
}

Received October 5, 2016 / Accepted January 7, 2017

\begin{abstract}
Hepatocellular carcinoma (HCC) is one of the most difficult cancer disease for diagnosis and treatment, with a low survival rate and high recurrence rate and mortality. Nuclear factor of activated T-cells 5 (NFAT5) is mediated by osmolality and proved to be a carcinogenic gene in some tumor. However in our study we considered NFAT5 as tumor suppressor of HCC. RT-qPCR was performed for NFAT5 expression in tumor tissues. $\mathrm{NaCl}$ was applied to make hyperosmotic treatment. We knockdowned and overexpressed NFAT5 to investigate its role in HCC. FCM was used for apoptosis assay. Transwell and scratch assay is proceeded for invasion.

NFAT5 is downregulated in HCC tissue and cell lines, besides, upregulated by hyperosmolality. NFAT5 promotes apoptosis by regulating PARP-1,BAX/BCL2 while inhibits invasion through EMT-related protein claudin-1 and fibronectin. Hyperosmolality is also a protective factor for HCC. We considered hyperosmolality exhibited his protective effect by inducing NFAT5.

In a word, NFAT5 inhibits invasion and promotes apoptosis in HCC, associated with osmolality.
\end{abstract}

Key words: NFAT5, HCC, hyperosmolality, invasion, apoptosis

Hepatocellular Carcinoma (HCC) is one of the most dangerous and severest cancer. It is the second leading cause of cancer-related death in China [1]. Despite the improvement of surgical technique, the median survival rate is $50 \%$ after 5 years [2]. Risk factor for HCC are mainly HBV infection, $\mathrm{HCV}$ infection, excessive alcohol consumption, and dietary exposure to aflatoxin [3]. Current treating methods, such as surgical resection, radiofrequency ablation (RFA) and transhepatic arterial chemotherapy and embolization (TACE) only control the patient with early HCC [4]. Thus the early diagnosis and early treatment is critical for HCC patients.

Nuclear factor of activated T-cells 5 (NFAT5) is ubiquitously expressed in all tissues especially those subjected to osmotic stress [5]. Till today NFAT5 has been proved playing an important role in several cancers. Guo K [6]learnt that NFAT promotes proliferation and migration of lung adenocarcinoma by regulating AQP5 expression. Researches of C. Kuper [7]proved NFAT5 contributes to proliferation and migration of renal carcinoma cell via mediating S100A4. J Li [8] illustrated that NFAT5 promotes breast cancer metastasis, and NFAT5 is maintained by miR-568.

Although the article mentioned all proved NFAT5 is a carcinogenic gene, we have discovered surprisingly that NFAT5 is a tumor suppressor in hepatocellular carcinoma. Our research made a deep research about the expression of NFAT5 in HCC, the role of NFAT5 in HCC occurrence and development, the mechanism that NFAT5 achieve its function, and how osmolality influences NFAT5 expression and function.

\section{Patients and methods}

Patients and specimens. All 50 patients of hepatocellular carcinoma accepted hepatectomy between September, 2015 and May, 2016 in Zhongnan Hospital of Wuhan University. All patients and those family have agreed to collect specimens. Tumor tissue and non-tumor tissue (distance with tumor border $>5 \mathrm{~cm}$ ) were collected immediately and store at $-80^{\circ} \mathrm{C}$ with RNA protective reagent. All patients receive initial treatment in our hospital. Type of tumor was confirm as hepatocellular carcinoma by biopsy, excluding cholangiocarcinoma.

Immunohistochemistry. Deparaffinized slides in 2 changes of xylene, one for $40 \mathrm{mins}$, the other for $20 \mathrm{mins}$. Transferred slides to $100 \%$ alcohol, $95 \%$ alcohol, $80 \%$ alcohol, $60 \%$ alcohol and $\mathrm{ddH}_{2} \mathrm{O}$ for $5 \mathrm{mins}$ each. Placed slides in vessel filled with antigen retrieval buffer and microwaved on middle for 
several minutes, then cooled at RT. Rinsed 5 mins twice with TBS. Then blocked endogenous peroxidase activity by incubating section in $3 \% \mathrm{H}_{2} \mathrm{O}_{2}$ solution in methanol for 30 mins Rinsed with TBS again. Blocked in $5 \%$ goat serum in TBS for 30min at RT. Drained slides for a few seconds and wiped round sections. Applied anti-NFAT5 antibody(HPA069711, 1:500, Sigma-Aldrich, USA) made up in TBS. Incubated 1 hour at RT. Rinsed 5 mins twice with TBST. Applied biotinconjugated Affinipure goat anti-rabbit antibody (SA00004-2, 1:1000, Proteintech, China) made up in TBS for 1 hour at RT. Rinsed again. Applied streptavidin peroxidase for 15 mins at RT. Rinsed twice. Developed with chromogen (DAB) at $\mathrm{RT}$, watched under microscope. Rinsed in running tap water for 5 mins. Counterstained in mayor's hematoxylin bath for 60 secs. Washed in water bath 8 times, then tap water for 3 mins. Dehydrated through $60 \%, 80 \%, 95 \%$ and $100 \%$ alcohol for 5 mins each. Transferred to xylene for 5 minutes. Air for 30 mins and then mounted.

Cell culture of HCC cell lines. Human HCC cell lines HepG2, Hep3B were purchase from Cell bank of Shanghai Institute of Cell Biology at the Chinese Academy of Science (Shanghai, China). HepG2 were cultured in 15\% FBS (Gibco, USA) and DMEM (Hyclone, Utah, USA) with 1\% Penicillin-Streptomycin. Hep3B were cultured in 15\% FBS and 1X Opti-MEN (Gibco, Grand Island, NY, USA) with 1\% Penicillin-Streptomycin. All cells were maintained at $37^{\circ} \mathrm{C}$ in a humidified atmosphere containing $5 \% \mathrm{CO}_{2}$. Cells were digested by Trypsin with $0.02 \%$ EDTA.

Transfection and hyperosmotic treatment. HepG2 were seeded at $30-40 \%$ confluency, then transfected by NFAT5 SiRNA (Viewsolid Biotech, Beijing, China) by GenMute siRNA transfection reagent(SignaGen Laboratories, MD, USA). Hep3B were were seeded at $60-70 \%$ confluency, then transfected by NFAT5 plasmid (NFAT5 Lentiviral Vector, pLenti-GIII-CMV-C-term-HA, Abm, Richmond, B.C., Canada) by Lipojet in vitro siRNA and DNA transfection kit (SignaGen Laboratories, MD, USA). 24 hours after transfected, cells were rinse with cold PBS and substituted medium. 48 hours after transfected, $\mathrm{NaCl}$ was added for hyperosmotic treatment for another 24 hours. Then transfected cell were used to proceed next trials.

RNA extraction and RT-qPCR. Total RNA was extracted from transfected cell and HCC tissue by TRIzol reagent (Biosharp, China). The concentration and quality of total RNA were examined by Nanodrop 2000 Spectrophotometer. RNA concentration is between $600 \sim 2500 \mathrm{ng} / \mu \mathrm{L}$, and $\mathrm{A} 260 / 280$ is between 1.8 2.0. Total RNA was reverse-transcripted by PrimeScript RT Master Mix (RR036A, Takara, Japan) into mRNA. Primers for Real-time quantitative PCR are listed below.

NFAT5 Fw: 5'-AATCGCCCAAGTCCCTCTAC-3'

NFAT5 Rev: 5'-GGTGGTAAAGGAGCTGCAAG-3'

$\beta$-Actin Fw: 5'-CCAACCGCGAGAAGATGA-3'

$\beta$-Actin Rev: 5'-CCAGAGGCGTACAGGGATAG-3'

Claudin-1 Fw: 5'-CCTCCTGGGAGTGATAGCAAT-3'

Claudin-1 Rev: 5'-GGCAACTAAAATAGCCAGACCT-3'
Fibronectin Fw: 5'-CGGTGGCTGTCAGTCAAG-3' Fibronectin Rev: 5'-AAACCTCGGCTTCCTCCATAA-3'

RT-qPCR trials were carried out on Bio-rad iQ5 by using SYBR green mix (Toyobo, Japan). The expression of mRNA was calculated based on threshold cycle and normalized with reference to the quantification of $\beta$-Actin.

Western blotting. Total Protein was extracted by RIPA and $1 \%$ PMSF for 30 mins lysis at $4^{\circ} \mathrm{C}$, then centrifuged with $12000 \mathrm{rpm}, 4^{\circ} \mathrm{C}$ for $15 \mathrm{~min}$. Collected supernatant liquid and boiled at $95^{\circ} \mathrm{C}$ for $5 \mathrm{mins}$ with $5 \mathrm{X}$ SDS loading buffer. Quantity of total protein was tested by Nanodrop 2000. 10-20 $\mu \mathrm{L}$ sample were loaded to SDS-PAGE with 80-120V. After SDS-PAGE, protein were transferred to PVDF membrane by $270 \mathrm{~mA}$ for 90 mins. Incubated membrane in blocking buffer (5\% skim milk in TBS-T) for 2 hours at RT. Incubated primary antibody at $4^{\circ} \mathrm{C}$ overnight. Washed membrane 5 mins for 3 times with TBS-T then incubated secondary antibody at $4^{\circ} \mathrm{C}$ for 1 hours. Washed membrane 5 mins for 3 times then developed color with ECL. Antibody used were listed below. NFAT5 rabbit polyclonal antibody (1:200, sc-13035, Santa Cruz Biotechnology Inc., Europe), Claudin-1 rabbit antibody (1:2000, 13255, Cell Signaling Technology, USA), Fibronectin mouse monoclonal antibody (1:100, sc-271098, Santa Cruz Biotechnology Inc., Europe), PARP-1 rabbit polyclonal antibody (1:1000, 13371-1-AP, Proteintech, China), goat anti-rabbit antibody $\operatorname{IgG}(1: 3000$, SA00001-2, Proteintech, China), goat anti-mouse antibody IgG (1:3000, SA00001-1, Proteintech, China).

Cell invasion assay. Transwell invasion assay: Matrigel (Corning, MA, USA) and Opti-MEM were mixture by 1:8 and added $100 \mu \mathrm{L}$ into upper chamber with transwell insert with an $8 \mu \mathrm{m}$ diameters (Corning, MA, USA). Opti-MEN with $15 \%$ FBS were added $600 \mu \mathrm{L}$ into lower chamber. Incubated at $37^{\circ} \mathrm{C}$ for 6 hours. Suspended transfected Hep3B cells with Opti-MEN only, then added $200 \mu \mathrm{L}$ into upper chamber. Incubated for 48 hours. Eliminated cells on the upper side of membrane. Cells on bottom side were fixed with methanol and stained with $0.1 \%$ crystal violet. Cells in 5 filter counted was averaged for result. Scratch assay: Cultured Hep3B cell after transfection and hyperosmotic treatment until 6-well plate was filled with monolayer cells. Scraped 3 straight lines with same width in all 6 wells. Took photos at 0 hours and 24 hours. Result was measured by the ratio of distance cell had invaded [ratio of invasion=1-(width of scratch in 24 hours)/ (width of scratch in 0 hour)].

Cell apoptosis assay. Transfected cells were dyed with Beyotime Annexin V-FITC Apoptosis Detection Kit (Beyotime Biotecnology, China). Suspended cells and centrifuged with $1000 \mathrm{~g}$ for 5 mins. Abandoned supernatant an washed with PBS buffer. Centrifuged with $1000 \mathrm{~g}$ for 5 mins. Added $195 \mu \mathrm{L}$ Annexin V-FITC buffer, $5 \mu \mathrm{L}$ and $10 \mu \mathrm{L}$ PI. Incubated without illumination for 20 mins. Tested by flow cytometer. The FCM apoptosis assay took place 72 hours after transfection (including 48 hours of transfecting treatment and 24 hours of osmolality treatment). Apoptosis rate equals to early apoptotic rate plus late apoptotic rate. 
Statistics. Paired t-test was performed to assess variance differences among NFAT5 expression in tumor and nontumor tissues for statistical significance. Unpaired t-test was performed to measure other trials. Symbol * represents the comparison of different treatment under same osmolality. $\mathrm{P}<0.05$ was considered as ${ }^{*}$, to indicate statistical significance, $\mathrm{P}<0.01$ was considered as ${ }^{* *}, \mathrm{P}<0.0001$ considered $^{* * *}$. Symbol \# represents the comparison of different osmolality with same treatment. Similarly, $\mathrm{P}<0.05$ was considered as \#, to indicate statistical significance, $\mathrm{P}<0.01$ was considered as \#, $\mathrm{P}<0.0001$ considered \#.

\section{Results}

NFAT5 expression was lower in HCC tissue than nontumor tissue. We first evaluated the expression of NFAT5 in HCC patients. HCC and non-tumor tissues were collected from 50 patients of HCC during hepatectomy, with approval of patients and their family. Immunohistochemistry was performed with these tissues. The result revealed that NFAT5 was downregluated in HCC tissues (Figure 1A), which was opposite to other tumors. Besides, 400x magnification picture showed NFAT5 expressed mostly in cytoplasm. To further confirm the expression of NFAT5, we processed the real-time quantitative PCR of NFAT5 in each pair of tissues. The result is in accordance with IHC. NFAT5 expressed in HCC tissue is significantly lower than non-tumor tissue $(\mathrm{p}<0.0001$, relative expression $=1.92 \pm 0.21$ in HCC, $7.63 \pm 0.51$ in NT, Mean difference $=-5.696$ ) (Figure 1B). The difference of NFAT5 expression between tumor and non-tumor tissues existed in most of the patients (Figure 1C, 1D). So these trials inferred NFAT5 played an important role in HCC development.

NFAT5 was regulated by osmolality in HCC cell lines. As mentioned before, NFAT5 was regulated by osmolality in various cells. To testify the same phenomenon in HCC cell lines, we applied hyperosmotic treatment to Hep3B cell lines. We added gradient concentration of $\mathrm{NaCl}$ into the medium, $0 \mathrm{mM}, 25 \mathrm{mM}, 50 \mathrm{mM}, 100 \mathrm{mM}$, and $200 \mathrm{mM}$. Western blot-

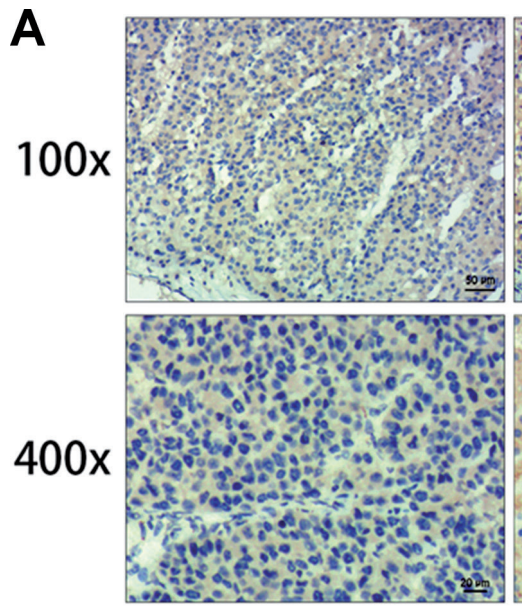

Hepatocarcinoma

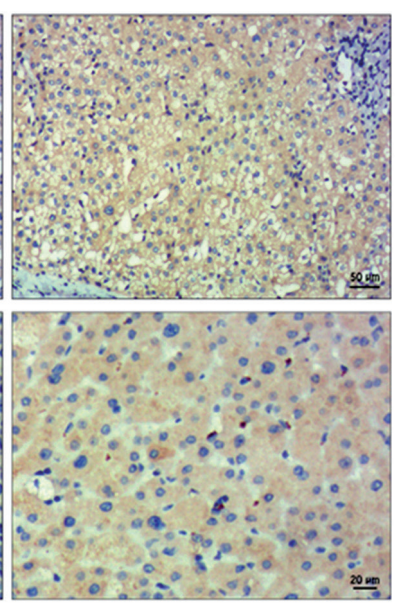

Non-tumor tissue

C
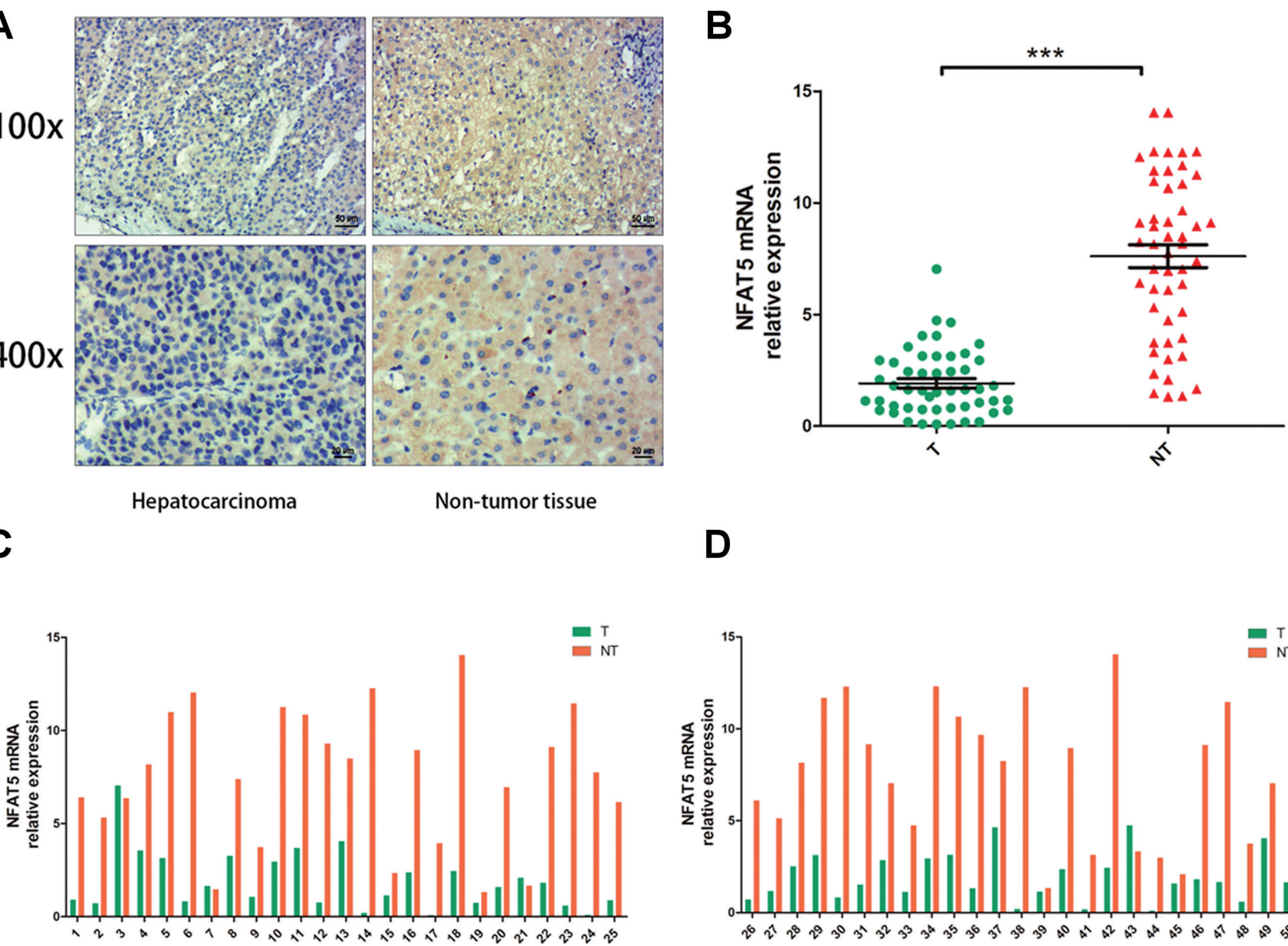

D

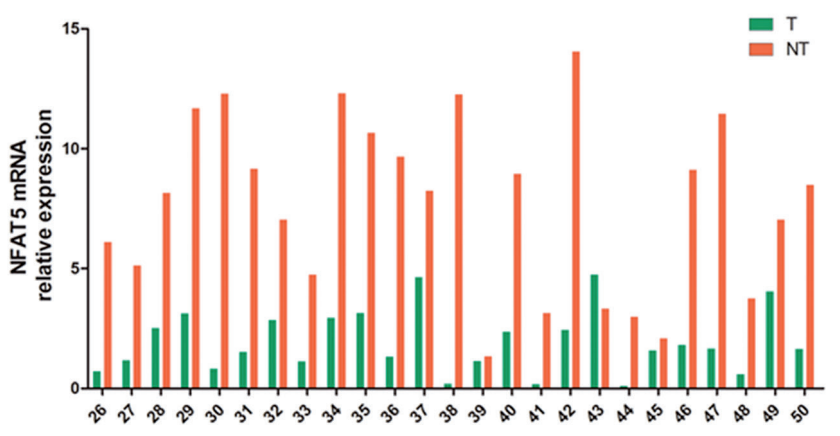

Figure 1. NFAT5 is downregulated in HCC tissues than non-tumor tissues. (A) Tumor and non-tumor tissues of 50 pairs of HCC patients were examined by immunohistochemistry with both magnification of 100x and 400x. (B) NFAT5 expression was evaluated by RT-qPCR for 50 pairs of tissues. (C, D) NFAT5 expression in each pairs of HCC and non-tumor tissues. 
ting showed that NFAT5 expressed most with $50 \mathrm{mM} \mathrm{NaCl}$ added (Figure $2 \mathrm{~B}$ ), compared to $0 \mathrm{mM}(\mathrm{p}<0.01)$. Gradients of $200 \mathrm{mM}$ could not express NFAT5, or even GAPDH, due to the destroying of hyperosmolality to Hep3B. Thus we only ran the RT-qPCR of former 4 gradients, and it revealed the same tendency with protein level (Figure 2A). NFAT5 mRNA is significantly higher in $50 \mathrm{mM}$ group than $0 \mathrm{mM}(\mathrm{p}<0.01)$. This implied osmolality might also involve in HCC development and growth. Besides, we testified NFAT5 expression in HCC cell lines, compared to normal liver cell L02. Both RT-qPCR and Western blotting showed that HepG2 was the highest $(\mathrm{p}<0.01)$ while Hep3B the lowest $(\mathrm{p}<0.0001)$ (Figure 2C, 2D), compared to L02.

NFAT5 and hyperosmolality promoted apoptosis of HCC cells. To evaluate the role of NFAT5 in cell apoptosis, we upregulated NFAT5 in Hep3B cell line with NFAT5 plasmid. We testified our hypothesis by flow cytometry method (FCM). We dyed the cells with Annexin V-FITC and PI for FCM apoptosis assay. As FCM showed, upregulation of NFAT5 promoted cell apoptosis in both osmotic condition [ $14.4 \%$ vs $8.6 \%$ of $0 \mathrm{mM}$, $\mathrm{p}<0.01 ; 30.56 \%$ vs $18.05 \%$ of $50 \mathrm{mM}, \mathrm{p}<0.0001$, transfection group(TG as followed) vs negative control(NC as followed), following comparison keeps the same order] (Figure 3A, 3B), and hyperosmolality caused more cell apoptosis(14.4\% vs
$30.56 \%$ in TG, $\mathrm{p}<0.0001 ; 8.6 \%$ vs $18.05 \%$ in $\mathrm{NC}, \mathrm{p}<0.0001$, $0 \mathrm{mM}$ vs $50 \mathrm{mM}$, following comparison keeps the same order). Next we silenced NFAT5 in HepG2 Cell line with SiRNA, leading to attenuation of apoptosis $(9.37 \%$ vs $14.91 \%$ in $0 \mathrm{mM}$, $\mathrm{p}<0.0001 ; 16.93 \%$ vs $25.56 \%$ in $50 \mathrm{mM}, \mathrm{p}<0.05$ ) (Figure 3D, $3 \mathrm{E})$. Moreover, hyperosmolality also induced apoptosis $(9.37 \%$ vs $16.93 \%$ in TG, $\mathrm{p}<0.05 ; 14.91 \%$ vs $25.56 \%$ in $\mathrm{NC}, \mathrm{p}<0.001$ ). Thus, we proved that NFAT5 promoted apoptosis of HCC, and hyperosmolality induced apoptosis. Poly (ADP-ribose) polymerase 1 (PARP-1), BAX/BCL-2 are considered as great important biomarker of apoptosis. During apoptosis, PARP-1 is cleaved into an $85 \mathrm{kDa}$ fragment, which has the real function to initiate downstream signals [9]. BAX is a protein leading to apoptosis while BCL-2 is a protein function as anti-apoptotic factor. So we detected PARP-1, BAX and BCL2 with Western Blotting assay. Apparently overexpressing NFAT5 induced cleaved PARP-1, BAX and reduced BCL-2 (Figure 3C). On the contrary silencing NFAT5 decreased cleaved PARP-1, BAX while increased BCL-2 (Figure 3F). Therefore NFAT5 promoted apoptosis of HCC, besides hyperosmolality induced apoptosis.

NFAT5 and hyperosmolality inhibited invasion of HCC cells. For exploring the function of NFAT5 in HCC invasion, weve designed several trials to make it clear. Transwell inva-
A

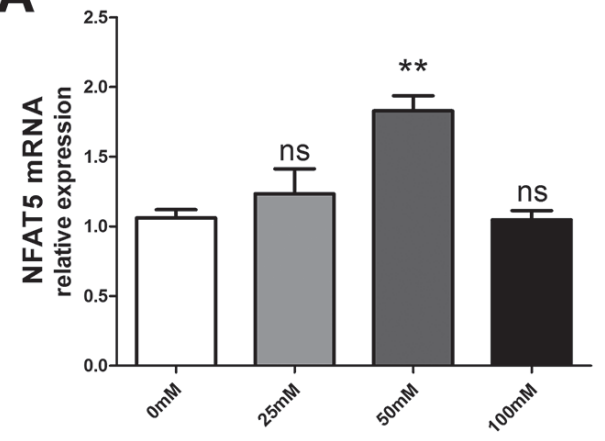

C

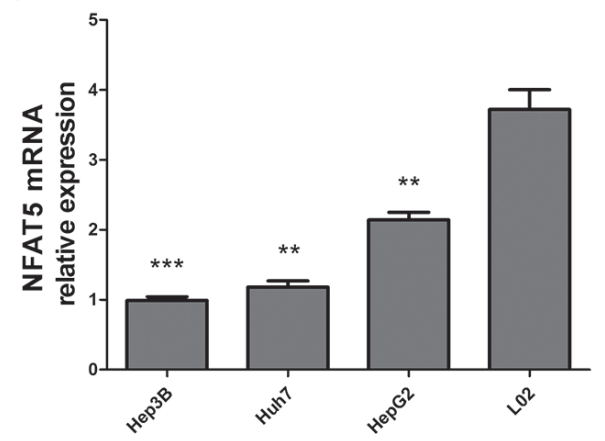

B

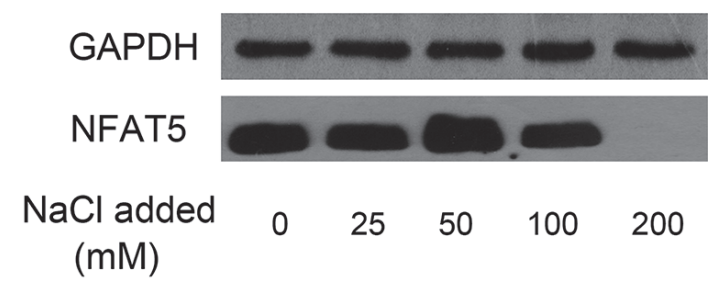

D

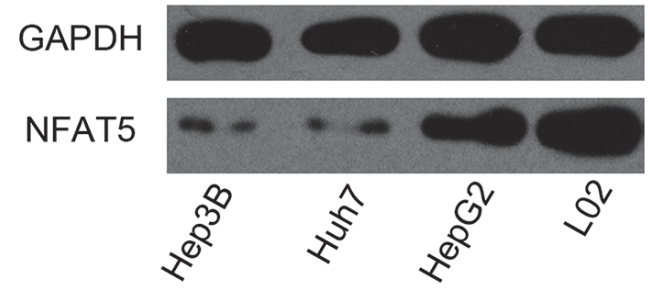

Figure 2. Hyperosmolality induces expression of NFAT5. (A) RT-qPCR showed NFAT5 expression in different osmolality (0mM, 25mM, 50mM, 100mM $\mathrm{NaCl}$ added). The comparison is between $0 \mathrm{mM}$ and other osmolality. (B) Western blotting assay for NFAT5 expression in different osmolality (0mM, $25 \mathrm{mM}, 50 \mathrm{mM}, 100 \mathrm{mM}, 200 \mathrm{mM} \mathrm{NaCl}$ added), and NFAT5 cannot expressed in under 200mM NaCl. (C) NFAT5 mRNA expression estimated by RTqPCR in different HCC cell lines and normal liver cell line L02. The comparison is between L02 and other HCC cell lines. (D) Western blotting assay of NFAT5 expression in different HCC cell lines and normal live cell line L02. 
sion assay was taken after overexpressing NFAT5. Since HepG2 has extremely weak ability of invasion, we haven't proceeded the knockdown assay. We took picture after 48 hours from transfected cell seeded into the upper chamber. Compared to negative control plasmid, overexpressing NFAT5 reduced cell invasion (Figure 4A). Cell counting showed an evident difference ( 36.33 vs 124.67 in $0 \mathrm{mM}, \mathrm{p}<0.0001,22.67$ vs 86 in $50 \mathrm{mM}, \mathrm{p}<0.01$ ) (Figure $4 \mathrm{~B}$ ). In isosmotic solution, HCC cells performed higher invasiveness $(p<0.05$ in TG, $p<0.01$ in NC). We also performed wound healing assay, also known as scratch assay, to evaluate the role of NFAT5 in cell invasion. Pictures were taken immediately after the scratch and also after 24 hours. It was clear that overexpressing NFAT5 reduced cell invasiveness (Figure 4C). We calculated the proportion of distance of cell invaded as the result. The difference had statistical significance ( $25.43 \%$ vs $44.29 \%$ in $0 \mathrm{mM}, \mathrm{p}<0.0001 ; 13.21 \%$ vs $33.26 \%$ in $50 \mathrm{mM},<0.0001$ ) (Figure $4 \mathrm{D}$ ). The isosmotic solution enhance the invasiveness of HCC cells $(p<0.01$ in TG, $\mathrm{p}=0.0002$ in NC) (Figure 4D). These trials strongly suggested that NFAT5 inhibited invasion of HCC cells, and hyperosmotic solution attenuated invasion.

NFAT5 inhibited invasion via claudin-1 and fibronectin. We further explored how NFAT5 inhibits invasion. Plenty of references were consulted. Finally, we chose two EMT-related biomarkers, claudin-1 and fibronectin. Claudin-1 is considered as epithelial marker [10], and fibronectin is a mesenchymal one [11]. Upregulation of NFAT5 suppressed fibronectin expression, in the mean while induced expression of claudin-1 in hyperosmotic solution (Figure 5A). We also performed RT-qPCR of these two EMT biomarker. The result mainly brought into accordance with Western blotting. Claudin-1 was only upregulated in hyperosmolality $(\mathrm{p}<0.05$, Figure $5 B)$, and fibronectin is suppressed in both osmotic solution $(\mathrm{p}<0.01$ in $0 \mathrm{mM}, \mathrm{p}<0.05$ in $50 \mathrm{mM}$, Figure $5 \mathrm{C}$ ). It was interesting that both claudin- 1 and fibronectin $m R N A$ were upregulated in hyperosmolality (claudin-1 increased in TG, $\mathrm{p}<0.05$; fibronectin increased in both TG and NC, $\mathrm{p}<0.0001$ and $\mathrm{p}<0.05$ ), relatively to isosmolality. We will discuss it in the next part about this phenomenon. In addition, we silenced NFAT5 to confirm this event. It illustrated that fibronectin was upregulated when NFAT5 was knocked down, in both osmotic solution (Figure 5D). Claudin-1 only changed in hyperosmolality but no difference in isosmolality, similar to overexpression assay (Figure 5D). RT-qPCR showed claudin-1 mRNA was depleted with NFAT5 silencing, only in hyperosmotic solution $(\mathrm{p}<0.0001)$, additionally induced by hyperosmolality $(\mathrm{p}<0.05$
A

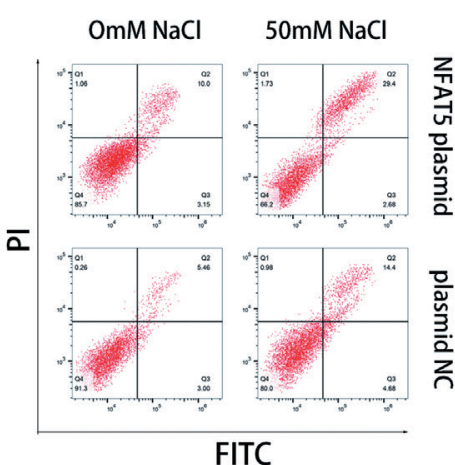

D

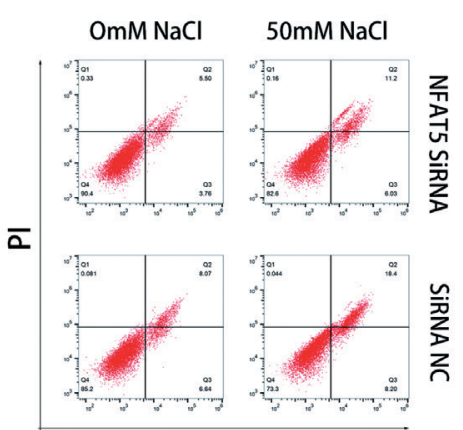

FITC

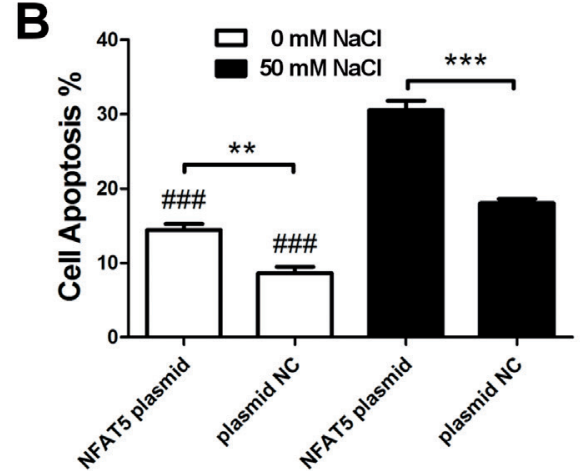

E

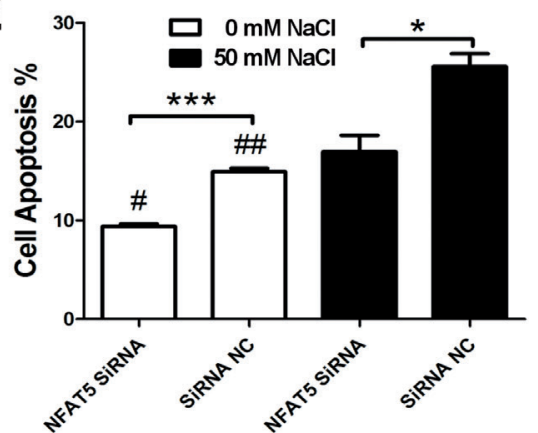

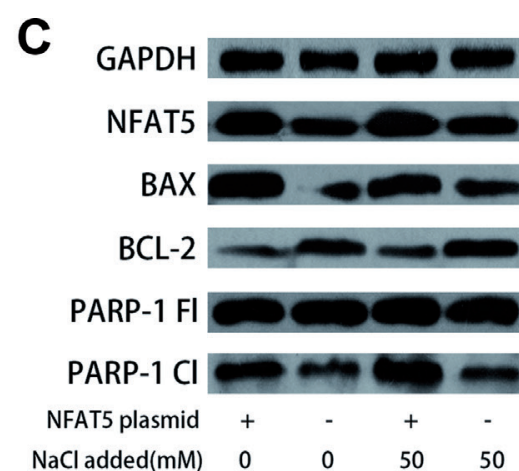

$\mathbf{F}$

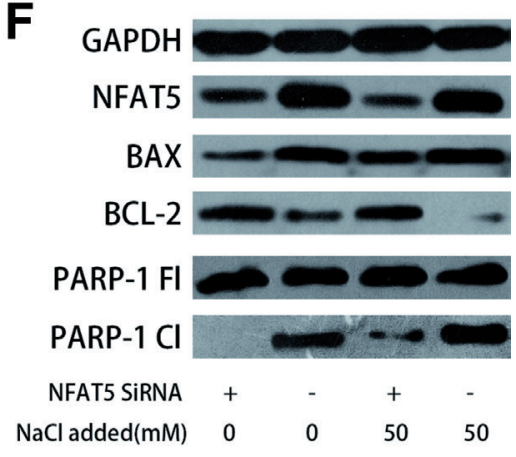

Figure 3. NFAT5 induces apoptosis of HCC cells. (A) FCM apoptosis assay of Hep3B cell lines after overexpression of NFAT5. (B) Statistical analysis of FCM results after overexpression. Apoptotic rate is equal to ratio of early and late apoptotic cells. (C) Western blotting for PARP-1, BAX, BCL2 after overexpression of NFAT5. PARP-1 Fl: Full length PARP-1; PARP-1 Cl: Cleaved PARP-1. The overexpression effect was verified by NFAT5 blot. (D) FCM apoptosis assay of HepG2 cell lines after knockdown of NFAT5. (E) Statistical analysis of FCM results after knockdown. Apoptotic rate is equal to ratio of early and late apoptotic cells. (F) Western blotting for PARP-1, BAX, BCL2 after knockdown of NFAT5. PARP-1 Fl: Full length PARP-1; PARP-1 Cl: Cleaved PARP-1. The knockdown effect was proved by NFAT5 blot. 
in TG; $\mathrm{p}<0.0001$ in NC) (Figure 5E). Fibronectin was upregulated since NFAT5 silencing $(\mathrm{p}<0.01$ in both $0 \mathrm{mM}$ and $50 \mathrm{mM})$. Furthermore, hyperosmolality subdued fibronectin mRNA expression ( $p<0.0001$ in TG; $p<0.01$ in NC). The expression of claudin- 1 and fibronectin varied generally in similar tendency both in protein and mRNA level in silencing trial.

\section{Discussion}

The occurrence and development of hepatocellular carcinoma is a complex progress including large number of genes, proteins and biochemical reactions. There are many genes has been reported in HCC, but NFAT5 was not mentioned till now. So we first revealed the role of NFAT5 in HCC.

In our study we focus on the function of NFAT5 in HCC. We first discovered a phenomenon totally on the contrary to the research before. Unlike other tumors, HCC cell expressed lower NFAT5 than non-tumor tissue. We proved it through 2 different methods and received the same results. We also noticed hyperosmolality promoted NFAT5 expression in HCC cell lines. NFAT5 also named as tonicity-responsive enhancer binding protein(TonEBP), or osmotic response element binding protein(OREBP) [12]. The signal pathway of NaCl-induced activation of NFAT5 contains ATK1 [13], cAbl [14], PI3K-1A [15]. This relation was proved in renal cells in plenty of researches $[7,16,17]$. Thus we planned to study whether osmolality could regulate tumor behavior of HCC via mediating NFAT5. Following we proceed the trial about apoptosis. As reported in recent articles, NFAT5 promotes proliferation of cancer cell, based on high expression of NFAT5 in cancer cell. Since NFAT5 is downregulated in HCC cells, we assumed that NFAT5 promoted apoptosis. FCM results is in accordance with our assumption. Next we observed that NFAT5 promotes apoptosis via regulating PARP-1, BAX and BCL-2, essential biomarkers of apoptosis. PARP- 1 is the downstream of BAX/BCL-2 in apoptotic pathway $[9,18]$. PARP-1 has been demonstrated to contribute DNA base excision repair and maintenance of genomic stability [19]. Cleaved PARP-1 induces apoptosis as mentioned above. The mechanism of how NFAT5 induces the apoptotic signaling pathway remains unclear. A. Adachi [20] evidenced NFAT5 regulated canonical Wnt pathway, contributing to cardiomyogenic differentiation. Q. Wang [21] also mentioned that NFAT5 repressed canonical Wnt/ $\beta$-catenin pathway. It is also reported that PARP-1 was involved in $\mathrm{Wnt} / \beta$-catenin signaling pathway [22]. These inferred NFAT5 probably induced apoptosis via regulating
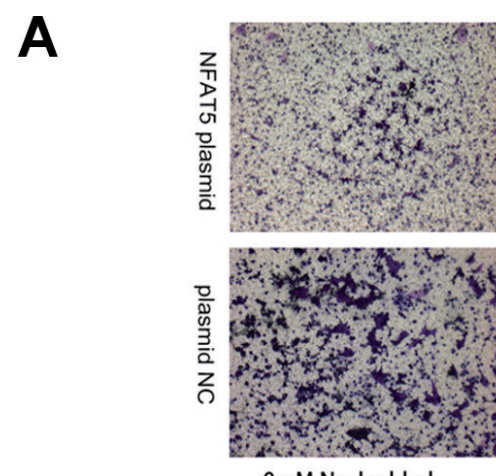

OmM Nacl added

C

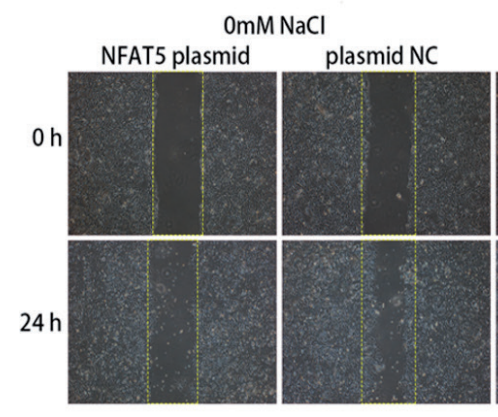

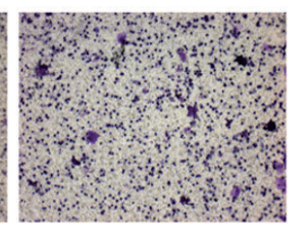

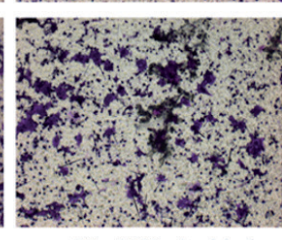

$50 \mathrm{mM} \mathrm{Nacl}$ added
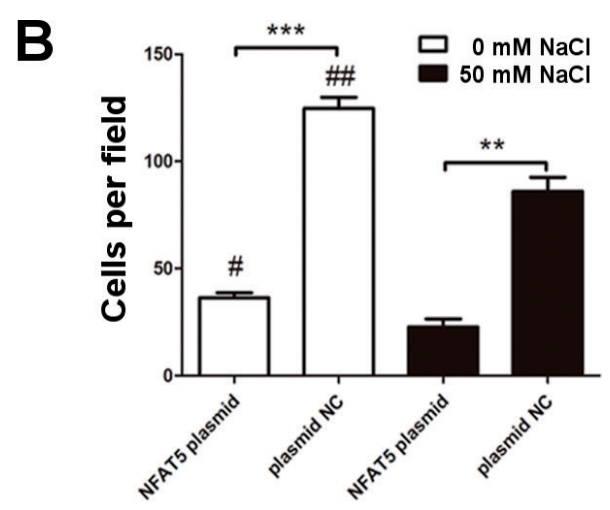

D

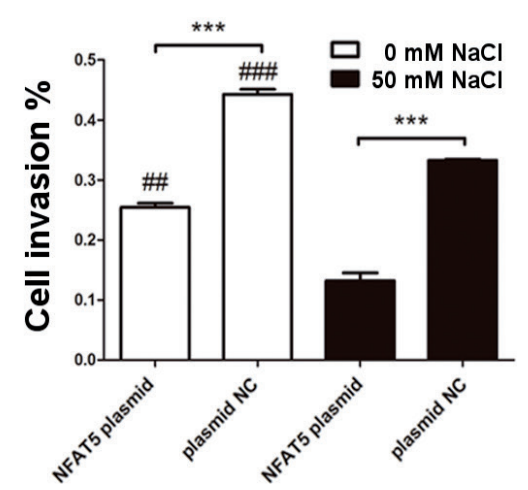

Figure 4. NFAT5 inhibits invasion of HCC cells. (A) Transwell invasion assay was performed after overexpression of NFAT5 in Hep3B. Pictures were taken after 48 hours. (B) Statistical analysis of Transwell invasion assay. Cell in 5 fields were calculated then averaged the number. (C) Scratch assay of Hep3B after overexpression of NFAT5. Pictures were taken in 0 and 24 hours. The yellow boxes with imaginary edge line of 24 hours is the same size as the box of same group in 0 hour. (D) Statistical analysis of scratch assay. Cell invasion rate=1-(width of scratch in $24 \mathrm{~h} /$ width of scratch in $0 \mathrm{~h}$ ), exhibited in percentage. 

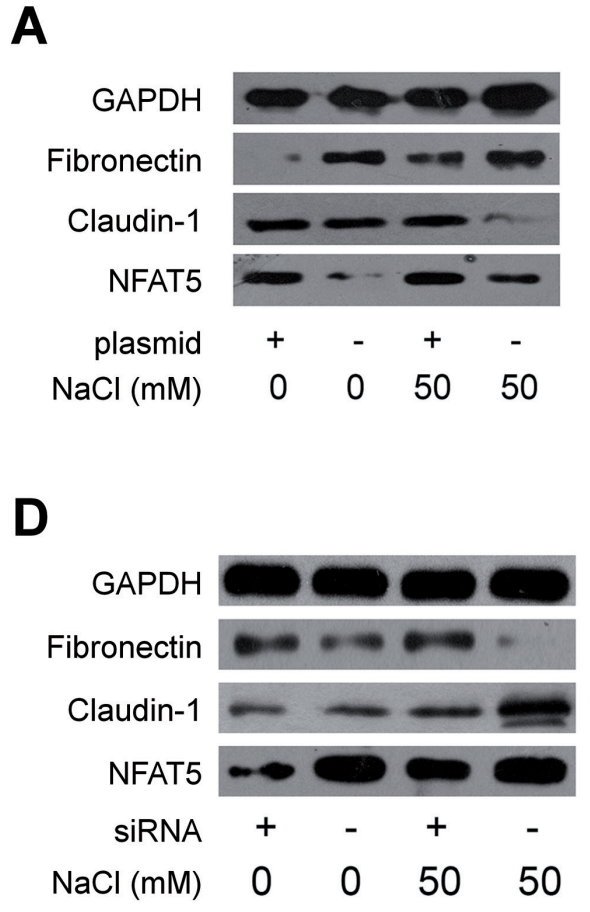

B

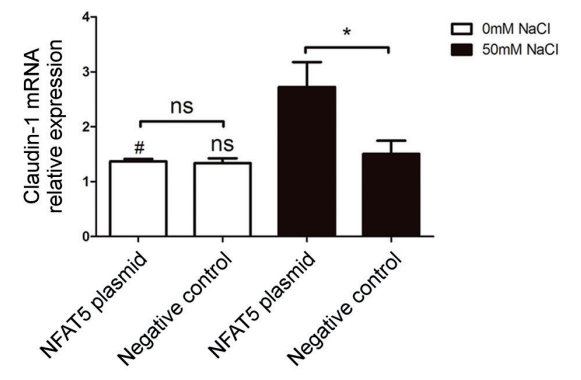

E

C

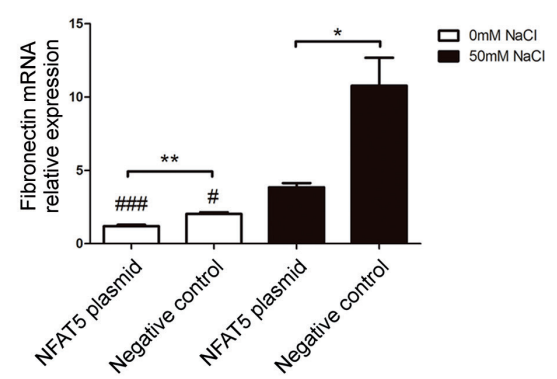

F
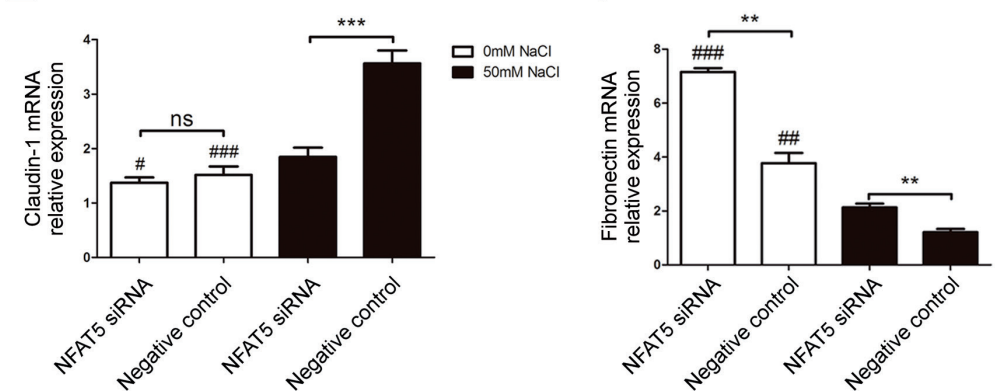

Figure 5. NFAT5 inhibits invasion via Claudin-1 and Fibronectin. (A) Western blotting of Fibronectin and Claudin-1 after overexpression of NFAT5 in Hep3B. Blot of NFAT5 confirmed NFAT5 was significantly overexpressed. (B) RT-qPCR of Claudin-1 after overexpression of NFAT5 in Hep3B. (C) RT-qPCR of Fibronectin after overexpression of NFAT5 in Hep3B. (D) Western blotting of Fibronectin and Claudin-1 after knockdown of NFAT5 in HepG2. Blot of NFAT5 confirmed knockdown of NFAT5 was validated. (E) RT-qPCR of Claudin-1 after knockdown of NFAT5 in HepG2. (F) RT-qPCR of Fibronectin after knockdown of NFAT5 in HepG2.

Wnt/ $\beta$-catenin signaling pathway. Perhaps we would make an advanced research about this hypothesis in the future.

HCC is a cancer with low 5 years survival rate because of its strong ability of invasion. HCC usually develops intrahepatic metastasis. Some severe HCC may invade to portal-vein. Distant metastasis of HCC happens seldom. However, extra hepatic metastasis, including portal-vein invasion, rank first in common mortality reason of HCC [23]. Thus invasiveness is a critical factor to evaluate danger of cancer disease. Transwell invasion assay and scratch assay obviously showed that NFAT5 was able to repress cell invasiveness. Knockdown of NFAT 5 contributed to more cell invasion, while overexpressed of NFAT5 inhibited cell invasion. For a deeper research, we studied two EMT-related protein, fibronectin and claudin-1, and their mRNA expression level in order to reveal the mechanism. Fibronectin is a mesenchymal biomarker $[11,24]$ with the same significance of vimentin and N-cadherin. Claudin-1 expresses by epithelial tissue [10], similarly to E-cadherin. Loss of claudin-1 is correlated with malignancy HCC [25]. According to the results, NFAT5 inversely mediated fibronectin expression. However, claudin-1 only induced by NFAT5 in hyperosmotic solution. We assumed that claudin-1 was more sensitive to NFAT5 with hyperosmolality inducing. Unfortunately no article has been found about this event. Perhaps some kind of pathway exists between these two proteins. Besides, the correlation between osmolality and EMT biomarkers seemed unclear. Claudin-1 and fibronectin didn't changed regularly with the variety of osmolality. The reason why hyperosmolality could have impact on invasiveness but the EMT markers still requires advanced study. Despite of it, we still confirmed that NFAT5 could mediate these two EMT biomarker. Whether NFAT5 directly binding to fibronectin or claudin-1 still requires more evidence to prove. H.D. Yang [26]demonstrated EMT are usually regulated by TGF- $\beta$. Meanwhile as N.R. Park [27] illustrated TGF- $\beta$ mediated EMT process with synergistic effect of CD 44 by activating $\beta$-catenin. Perhaps NFAT5 regulates TGF- $\beta$ expression so as to attenuate HCC cell invasion. There are some reports about interaction between NFAT5 and TGF- $\beta$. A. Winges [28] proved TGF- $\beta$ mediated aldose reductase $(A R)$ in hyperosmolality via regulating NFAT5. M. Veltmann [29] also found out both TGF- $\beta$ and NFAT5 can regulate angiogenic factors, such as VEGF, bFGF, HB-EGF in hyperosmotic solution. Whereas it requires more evidence to confirm the interaction.

In each trial, we applied osmotic factor in it. As we could learn from the results, hyperosmolality induced apoptosis and suppressed invasiveness. According to Figure 3B, apoptotic rate both raised in transfection group or negative control group, with the osmolality increasing (\#\# in TG and NC). Additionally NFAT5-induced apoptosis was enhanced since 
osmolality increased (** in $0 \mathrm{mM}$ vs ${ }^{* * *}$ in $\left.50 \mathrm{mM}\right)$. We considered hyperosmolality intensified the overexpression of NFAT5 which caused this phenomenon. On the other hand, Figure 3E manifested a weaken effect of knockdown in hyperosmotic solution (\# in TG and \#\# in NC; ${ }^{* * *}$ in $0 \mathrm{mM}$ vs ${ }^{*}$ in $50 \mathrm{mM}$ ). This implied that hyperosmolality and NFAT5 couldn't perform a synergistic effect on apoptosis. We evaluated the invasion assay in the same way. In Transwell assay, hyperosmolality enforced the suppressing effect of NFAT5 on invasion (\# in TG, \#\# in NC; ${ }^{* * *}$ in $0 \mathrm{mM}$, ${ }^{* *}$ in $50 \mathrm{mM}$ ), which meant $\mathrm{HCC}$ cell invasiveness was lower in hyperosmolality. Same phenomenon was observed in scratch assay (\#\# in TG, \#\#\# in NC). All these data implied that NFAT5 promoted apoptosis and repressed invasion, in the meantime induced by hyperosmolality. Based on previous researches, hyperosmolality induced NFAT5 by mediating MAPK p38, JNK, ERK1/2 signaling pathway $[7,16$, $28,30]$. Including the signal mentioned above (PI3K, c-Abl, ATK1), the activation of NFAT5 induced by $\mathrm{NaCl}$ is a complex biochemical reaction with a net of signaling pathways. Theoretically, hyperosmotic solution contributes to attenuating progress of HCC. In fact, hyperosmotic will damage cells, no matter normal or tumor cells. High $\mathrm{NaCl}$ concentration could cause more disease such as hypertension. It makes a severe damage to blood vessels. Increasing osmolality around hepatocellular carcinoma and maintain it in a moderate range may be benefit for HCC treatment.

Acknowledgements: This study was supported by National Natural Science Foundation of China. Grant No. 81272692.

\section{References}

[1] YUAN SX, YANG F, YANG Y, TAO QF, ZHANG J et al. Long noncoding RNA associated with microvascular invasion in hepatocellular carcinoma promotes angiogenesis and serves as a predictor for hepatocellular carcinoma patients' poor recurrence-free survival after hepatectomy. Hepatology 2012; 56: 2231-2241. https://doi.org/10.1002/hep.25895

[2] TAKAYAMA T. Surgical treatment for hepatocellular carcinoma. Jpn J Clin Oncol 2011; 41: 447-454. https://doi. org/10.1093/jico/hyr016

[3] MA L, CHUA MS, ANDRISANI O, SO S. Epigenetics in hepatocellular carcinoma: an update and future therapy perspectives. World J Gastroenterol 2014; 20: 333-345. https:// doi.org/10.3748/wjg.v20.i2.333

[4] WANG S, ZHU Y, HE H, LIU J, XU L et al. Sorafenib suppresses growth and survival of hepatoma cells by accelerating degradation of enhancer of zeste homolog 2. Cancer Sci 2013; 104: 750-759. https://doi.org/10.1111/cas.12132

[5] DOBIERZEWSKA A, PALOMINOS M, IRARRAZABAL CE, SANCHEZ M, LOZANO M et al. NFAT5 Is Up-Regulated by Hypoxia: Possible Implications in Preeclampsia and Intrauterine Growth Restriction. Biol Reprod 2015; 93: 14. https:// doi.org/10.1095/biolreprod.114.124644

[6] GUO K, JIN F. NFAT5 promotes proliferation and migration of lung adenocarcinoma cells in part through regulating
AQP5 expression. Biochem Biophys Res Communic 2015; 465: 644-649. https://doi.org/10.1016/j.bbrc.2015.08.078

[7] KUPER C, BECK FX, NEUHOFER W. NFAT5-mediated expression of S100A4 contributes to proliferation and migration of renal carcinoma cells. Front Physiol 2014; 5: 293. https:// doi.org/10.3389/fphys.2014.00293

[8] LI JT, WANG LF, ZHAO YL, YANG T, LI W et al. Nuclear factor of activated $\mathrm{T}$ cells 5 maintained by Hotair suppression of miR-568 upregulates $\mathrm{S} 100$ calcium binding protein A4 to promote breast cancer metastasis. Breast Cancer Res 2014; 16: 454. https://doi.org/10.1186/s13058-014-0454-2

[9] LU Z, CAO S, ZHOU H, HUA L, ZHANG S et al. Mechanism of Arctigenin-Induced Specific Cytotoxicity against Human Hepatocellular Carcinoma Cell Lines: Hep G2 and SMMC7721. PLoS One 2015; 10: e0125727. https://doi. org/10.1371/journal.pone.0125727

[10] HU WH, HU Z, SHEN X, DONG LY, ZHOU WZ et al. C5a receptor enhances hepatocellular carcinoma cell invasiveness via activating ERK1/2-mediated epithelial-mesenchymal transition. Exp Mol Pathol 2016; 100: 101-108. https://doi. org/10.1016/j.yexmp.2015.10.001

[11] WANG Z, QU L, DENG B, SUN X, WU S et al. STYK1 promotes epithelial-mesenchymal transition and tumor metastasis in human hepatocellular carcinoma through MEK/ ERK and PI3K/AKT signaling. Sci Rep 2016; 6: 33205. https:// doi.org/10.1038/srep33205

[12] NEUHOFER W. Role of NFAT5 in inflammatory disorders associated with osmotic stress. Curr Genomics 2010; 11: 584-590. https://doi.org/10.2174/138920210793360961

[13] ROTH I, LEROY V, KWON HM, MARTIN PY, FERAILLE E et al. Osmoprotective transcription factor NFAT5/TonEBP modulates nuclear factor-kappaB activity. Mol Biol Cell 2010; 21: 3459-3474. https://doi.org/10.1091/mbc.E10-02-0133

[14] GALLAZZINI M, YU MJ, GUNARATNE R, BURG MB, FERRARIS JD. c-Abl mediates high NaCl-induced phosphorylation and activation of the transcription factor TonEBP/ OREBP. FASEB 2010; 24: 4325-4335. https://doi.org/10.1096/ f. $10-157362$

[15] IRARRAZABAL CE, BURG MB, WARD SG, FERRARIS JD. Phosphatidylinositol 3-kinase mediates activation of ATM by high $\mathrm{NaCl}$ and by ionizing radiation: Role in osmoprotective transcriptional regulation. Proc Natl Acad Sci U S A 2006; 103: 8882-8887. https://doi.org/10.1073/pnas.0602911103

[16] ZHOU X, WANG H, BURG MB, FERRARIS JD. Inhibitory phosphorylation of GSK-3beta by AKT, PKA, and PI3K contributes to high $\mathrm{NaCl}$-induced activation of the transcription factor NFAT5 (TonEBP/OREBP). Am J Physiol Renal Physiol 2013; 304: F908-917. https://doi.org/10.1152/ajpre$\underline{\text { nal.00591.2012 }}$

[17] CHUA OW, WONG KK, KO BC, CHUNG SK, CHOW BK et al. Role of nuclear factor of activated T-cells 5 in regulating hypertonic-mediated secretin receptor expression in kidney collecting duct cells. Biochim Biophys 2016; 1859: 922-932. https://doi.org/10.1016/j.bbagrm.2015.12.009

[18] CARDNELL RJ, FENG Y, MUKHERJEE S, DIAO L, TONG $\mathrm{P}$ et al. Activation of the PI3K/mTOR Pathway following PARP Inhibition in Small Cell Lung Cancer. PLoS One. 
2016;11(4):e0152584. https://doi.org/10.1371/journal. pone. 0152584

[19] MATHEWS MT, BERK BC. PARP-1 inhibition prevents oxidative and nitrosative stress-induced endothelial cell death via transactivation of the VEGF receptor 2. Arterioscler Thromb Vasc Biol 2008; 28: 711-717. https://doi.org/10.1161/ ATVBAHA.107.156406

[20] ADACHI A, TAKAHASHI T, OGATA T, IMOTO-TSUBAKIMOTO $\mathrm{H}$, NAKANISHI $\mathrm{N}$ et al. NFAT5 regulates the canonical Wnt pathway and is required for cardiomyogenic differentiation. Biochem Biophys Res Commun 2012; 426: 317-323. https://doi.org/10.1016/j.bbrc.2012.08.069

[21] WANG Q1, ZHOU Y, RYCHAHOU P, LIU C, WEISS HL et al. NFAT5 represses canonical Wnt signaling via inhibition of beta-catenin acetylation and participates in regulating intestinal cell differentiation. Cell Death Dis 2013; 4: e671. https://doi.org/10.1038/cddis.2013.202

[22] WU X, DENG G, LI M, LI Y, MA C et al. Wnt/beta-catenin signaling reduces Bacillus Calmette-Guerin-induced macrophage necrosis through a ROS -mediated PARP/AIFdependent pathway. BMC Immunol 2015; 16: 16. https://doi. org/10.1186/s12865-015-0080-5

[23] JALBANI IK, NAZIM SM, TARIQ MU, ABBAS F. Adrenalectomy for solitary metastasis of Hepatocellular carcinoma post liver transplantation: Case report and literature review. Pak J Med Sci 2016; 32: 1044-1046. https://doi.org/10.12669/ pjms.324.10339

[24] WANG SC, LIN XL, LI J, ZHANG TT, WANG HY et al. MicroRNA-122 triggers mesenchymal-epithelial transition and suppresses hepatocellular carcinoma cell motility and invasion by targeting RhoA. PLoS One 2014; 9: e101330. https://doi. org/10.1371/journal.pone.0101330

[25] HIGASHI Y, SUZUKI S, SAKAGUCHI T, NAKAMURA T, BABA $S$ et al. Loss of claudin-1 expression correlates with malignancy of hepatocellular carcinoma. J Surg Res 2007; 139: 68-76. https://doi.org/10.1016/j.jss.2006.08.038

[26] YANG HD, KIM PJ, EUN JW, SHEN Q, KIM HS et al. Oncogenic potential of histone-variant H2A.Z.1 and its regulatory role in cell cycle and epithelial-mesenchymal transition in liver cancer. Oncotarget 2016; 7: 11412-11423.

[27] PARK NR, CHA JH, JANG JW, et al. Synergistic effects of CD44 and TGF-beta1 through AKT/GSK-3beta/beta-catenin signaling during epithelial-mesenchymal transition in liver cancer cells. Biochem Biophys Research Commun 2016; 477: 568-574. https://doi.org/10.1016/j.bbrc.2016.06.077

[28] WINGES A, GARCIA TB, PRAGER P, WIEDEMANN P, KOHEN L et al. Osmotic expression of aldose reductase in retinal pigment epithelial cells: involvement of NFAT5. Graefes Arch Clin Exp Exp Ophthalmol 2016; 254: 2387-2400. https://doi. org/10.1007/s00417-016-3492-x

[29] VELTMANN M, HOLLBORN M, REICHENBACH A, WIEDEMANN P, KOHEN L et al. Osmotic Induction of Angiogenic Growth Factor Expression in Human Retinal Pigment Epithelial Cells. PLoS One 2016; 11: e0147312. https:// doi.org/10.1371/journal.pone.0147312

[30] WANG H, FERRARIS JD, KLEIN JD, SANDS JM, BURG $\mathrm{MB}$ et al. PKC-alpha contributes to high $\mathrm{NaCl}$-induced activation of NFAT5 (TonEBP/OREBP) through MAPK ERK1/2. Am J Physiol Renal Physiol 2015; 308: F140-148. https://doi. org/10.1152/ajprenal.00471.2014 